\title{
FUNGSI PENGAWASAN KOMISARIS TERKAIT KESEHATAN BANK PERKREDITAN RAKYAT: PENDEKATAN GOOD CORPORATE GOVERNANCE DAN ASAS ITIKAD BAIK
}

\author{
Ni Ketut Supasti Dharmawan'1, I Gede Agus Kurniawan² \\ Fakultas Hukum Universitas Udayana - Bali \\ J alan Bali No. 1 Sanglah Denpasar - Bali, 80114 \\ arasswk@yahoo.com
}

\begin{abstract}
The health of bank including Rural Banks cannot be separated from the role of the Commissioner in the governance of banking institutions. This paper aims to elaborate the function and responsibility of the Board of Commissioners in managing a healthy Rural Bank in relation to the principles of GCG and the Good Faith principle. The method used to analyze the relevance of the principle of good faith with GCG for health of bank is the normative method. The types of statutes approach and concept approaches, including the concept of CSR used in this study. The results of the study indicate that the Commissioner as a representative of shareholders plays an important role in the framework of GCG and the principle of good faith, namely being responsible for independent supervision and control functions of the Board of Directors who carry out management in order to realize and sustainably improve the health of the bank.
\end{abstract}

Keywords: GCG; Principles of Good Faith; Commissioners; the Health of Bank.

\begin{abstract}
ABSTRAK
Kesehatan bank termasuk Bank Perkreditan Rakyat tidak bisa dilepaskan dari peran Komisaris dalam tata kelola institusi perbankan. Tulisan ini bertujuan untuk mengelaborasi fungsi kontrol dan tanggung jawab Komisaris dalam pengelolaan Bank Perkreditan Rakyat yang sehat dalam kaitannya dengan prinsip GCG serta Asas Itikad Baik. Metode yang digunakan untuk menganalisis relevansi antara asas itikad baik dengan GCG bagi kesehatan bank adalah metode normatif. Jenis pendekatan perundangundangan serta pendekatan konsep, diantaranya konsep CSR dipergunakan dalam studi ini. Hasil studi menunjukkan bahwa Komisaris sebagai wakil pemegang saham berperan penting dalam rangka GCG dan asas itikad baik yaitu bertanggungjawab melakukan pengawasan secara independen dan fungsi kontrol terhadap Dewan Direksi yang menjalankan pengelolaan dalam rangka mewujudkan dan secara berkesinambungan meningkatkan kesehatan bank.
\end{abstract}

Kata kunci: GCG; Asas Itikad Baik; Komisaris; Kesehatan Bank.

\footnotetext{
${ }^{1}$ Dosen Fakultas Hukum Universitas Udayana Denpasar Bali

2 Dosen Fakultas Hukum Universitas Udayana Denpasar Bali
} 


\section{A. PENDAHULUAN}

Keberadaan bisnis perbankan, temasuk Bank Perkreditan Rakyat (BPR) tidak dapat dipungkiri berkaitan dengan sektor bisnis lainnya, seperti sektor property. Ketika bisnis property berkembang pesat maka sektor perbankanpun juga berperan serta di dalamnya. Demikian pula ketika bisnis property mengalami keterpurukan, sektor bank, tidak terkecuali BPR juga rentan terkena imbas, khususnya mempengaruhi tingkat kesehatan bank karena meningkatnya kredit bermasalah (Non-Performing Loan). Seperti contoh, pada tahun 2017 pertumbuhan BPR di Bali cenderung melambat jika dibandingkan dengan tahun sebelumnya. Sementara itu, di sisi lainnya justru terjadi peningkatan NPL atau kredit bermasalah yang acapkali dipersamakan dngan kredit macet hingga mencapai $48 \%$ (Mustofa, 2018). NPL BPR di Bali hingga tahun 2018 masih tetap tinggi jika dibandingkan tahun sebelumnya. Pada NPL BPR pada bulan Desember 2017 sebesar 6,77\% dan meningkat menjadi 7,81 \% pada Maret 2018. Tingginya tingkat NPL, menurut Kepala Otoritas Jasa Keuangan (OJK) Regional Bali Nusra disebabkan salah satunya oleh lemahnya SDM BPR. Dalam penyaluran kredit belum dilaksanakan secara baik analisis kredit. Faktor internal dan eksternal turut mempengaruhi tingginya tingkat NPL pada BPR. Faktor internal, seperti faktor operasional serta SDM internal kontrol yang belum memadai termasuk Direksi dan Komisaris acapkalia menjadikan pemberian kredit kurang bijaksana. Sementara itu, faktor eksternal meskipun pertumbuhan ekonomi tinggi namun tidak merata juga menjadi faktor penyebab tingkat NPL pada BPR menjadi tinggi (Citta Maya, 2018).

Dengan mencermati fenomena meningkatnya NPL pada BPR, khususnya yang dipengaruhi oleh faktor internal baik yang berkaitan dengan jumlah SDM yang belum memadai hingga kemampuan dan kurang cermatnya kinerja SDM pada BPR dalam menganalisis dan menyalurkan kredit, dapat dikemukakan bahwa pemahaman operasional dan tata kelola institusi yang profesional berbasis Good Corporate Governance (GCG) dalam kaitannya dengan memaksimalkan Asas Itikad Baik dalam pengelolaan BPR, termasuk fungsi kontrol dan pengawasan dari Komisaris dalam rangka kesehatan BPR menjadi sangat penting untuk dikaji secara lebih mendalam. Sehubungan dengan hal tersebut, kajian penting dalam tulisan ini meliputi: Bagaimanakah relevansi prinsip GCG dan Asas Itikad Baik dengan kesehatan BPR? Bagaimanakah tanggungjawab Komisari dalam kaitannya dengan fungsi pengawasan tata kelola BPR dalam persepektif GCG dan Asas Itikad Baik? 
Kualitas manajemen tata kelola operasional perbankan berperan penting dalam rangka menumbuhkembangkan industri perbankan yang kuat dan sehat. Studi Miswan Gumanti dan Desi Handayani mengindikasikan bahwa peningkatan kualitas GCG diperlukan dalam rangka peningkatan kualitas manajemen bank agar praktik perbankan yang tidak sehat dapat diminimalisir. Apabila bank tidak memiliki manajemen yang baik dapat menimbulkan risiko operasional baik pada sistem, prosedur maupun sumber daya manusia (Gumanti, 2017). Keterkaitan antara GCG dengan kokohnya industri perbankan juga dikemukakan dalam studi yang dilakukan oleh Ayu Anita Ekaristi Oroh, dkk yang mengemukakan bahwa pelaksanaan prinsipprinsip GCG secara total mendukung kekuatan industri perbankan. GCG yang tidak efektif dapat menyebabkan kegagalan perusahaan perbankan, sehubungan dengan hal tersebut internal audit merupakan katalis untuk meningkatkan efesiensi organisasi. Peran internal audit dapat mendorong transparansi dan integritas, akuntabilitas, pertanggungjawaban, idependensi serta fairness (Oroh dkk., 2018). Dengan mencermati Organisation for Economic Co-operation and Development (OECD), dapat dikemukakan ada lima aspek penting pada konsep GCG yaitu: transparency, accountability, responsibility, independency, fairness (Emirson, 2006). Kajian tentang GCG bagi perusahaan khususnya perbankan telah dilakukan bagi para penstudi hukum, namun dalam tulisan ini lebih berfokus pada pengkajian dengan pendekatan pertanggungjawaban serta fungsi pengawas Komisaris sebagai perwakilan pemegang saham pada sektor bank, khususnya BPR berkaitan dengan peningkatan kualitas GCG dan relevansinya dengan Asas itikad baik dalam tata kelola perbankan.

Metode penelitian yang relevan dipergunakan dalam mengkaji tanggungjawab komisaris dalam kaitannya dengan fungsi pengawasan pengelolaan BPR yang memperhatikan elemen-elemen GCG dan Asas Itikad baik adalah metode penelitian normative. Pendekatan konsep, khususnya konsep GCG serta pendekatan perundang-undangan relevan dipergunakan dalam studi ini.

Studi ini bertujuan untuk mengkaji dan mengelaborasi secara lebih mendalam tentang tanggung jawab serta fungsi pengawasan Komisaris terkait kualitas GCG dan asas itikad baik dalam hubungannya dengan kesehatan BPR dalam rangka meminimalisasi tingkat kredit bermasalah atau NPL. 


\section{B. PEMBAHASAN}

\section{a. Prinsip GCG dan Asas Itikad Baik dalam Perbankan}

Bank memiliki peranan yang strategis dalam kehidupan perekonomian masyarakat. Melalui operasional bank, masyarakat dapat meminjam uang atau yang dikenal dengan kredit, fungsi bank menyalurkan dana, maupun masyarakat dapat menabung yaitu fungsi bank menghimpun dana, dan bahkan dalam perkembangannya dalam kehidupan global sekarang ini layanan jasa perbankan semakin beragam dan inovatif. Sehubungan dengan hal tersebut dibutuhkan adanya sektor perbankan yang stabil dan sehat. Dalam rangka stabilitas dan kesehatan bank, keberadaan Prinsip-prinsip Tata Kelola Perusahaan yang Baik (GCG) memainkan peran mendasar yang penting.

Sektor perbankan yang tidak didukung dengan GCG sangat rentan berdampak pada memburuknya kesehatan perbankan, bahkan bisa meluas hingga krisis keuangan global. Reformasi yang menghasilkan berbagai regulasi terkait GCG sudah banyak dilakukan di beberapa negara. Namun, acapkali juga dipertanyakan jika perubahan regulasi tanpa disertai oleh mekanisme yang baik juga tidak dapat dihindari terjadinya krisis kembali dalam sektor perbankan.

Studi terbaru di Swiss mengungkapkan bahwa rata-rata karyawan bank internasional besar akan berperilaku jujur dalam kondisi yang terkontrol. Namun, ketika semakin meningkat dibutuhkan profesionalitas mereka sebagai karyawan bank, sebagian besar dari mereka menjadi tidak jujur (Cohn dkk., 2014). Penelitian terkait kontrol pada karyawan perusahaan di industri lain, tidak menunjukkan pola perilaku yang sama. Para penstudi menyimpulkan bahwa terdapat budaya tidak baik yang berlaku di industri perbankan yang melemahkan dan merongrong standar kejujuran mereka.

Para pemerhati industri, termasuk the Bank Governance Leadership Network (www.Tapestrynetworks.com) and the Basel Committee on Banking Supervision (BASEL) (www.bis.org), menganjurkan kepada industri dan regulator untuk fokus pada reformasi Tata Kelola Perusahaan yang baik (GCG) yang akan membangun kembali budaya kejujuran. Para bankir telah bergabung dengan bankir global yang dihormati, termasuk Sir David Walker (Barclays Chairman at the Federal Reserve Bank of New) York(Walker, 2014) dan Andrew Bailey (CEO of the United Kingdom's Prudential Regulation Authority)(Bailey, 2014) yang keduanya memandang bahwa ada kebutuhan mendesak bagi industri untuk mengatasi kekurangan dalam budaya perbankan dan membangun kembali kepercayaan dunia perbankan. David Walker memberikan paradigma yang berguna untuk 
menganalisis GCG dalam konteks perbankan,

Terkait dengan GCG, OECD dengan mengedepankan tiga komponen dalam mendefinisikan sebagi berikut: 'Procedures and GCG. Pertama, komponen stabilitas keuangan processes according to which an organization is dan ketahanan sistem perbankan internasional. directed and controlled. The corporate Berkaitan dengan komponen pertama ini telah governance structure specifies the distribution of dilakukan refomasi dan pengaturan. Kedua, rights and responsibilities among the different komponen tentang efisiensi operasional dan participants in the organization - such as the transparansi bank. Perbaikan yang mengarah ke arah bidang ini juga telah dilakukan, terkait dengan proses, sistem, dan auditabilitas perbankan. Ketiga, unsur kepercayaan, yang berkaitan dengan nilai-nilai dan perilaku. Ketiga komponen tersebut merupakan hal penting sebagai dasar alasan dalam bertindak, aturan yang memadai, peningkatan kepatuhan dan persyaratan audit. Memperbaiki sistem keuangan membutuhkan lebih dari sekedar memperbaiki modal dan standar likuiditas. Standar tata kelola, perilaku, dan struktur insentif yang tepat semuanya sangat penting. Studi IoneliaAlexandra Feldioreanua and Crina Seria tahun 2015 mengindikasikan dalam rangka pelaksanaan GCG bahwa tingkat pengungkapan tata kelola perusahaan yang tinggi, termasuk sorotan keuangan dapat dianggap sebagai upaya untuk mengurangi kemungkinan ditipu, bahkan dapat meningkatkan atau setidaknya mempertahankan kepercayaan diri para pemangku kepentingan (Feldioreanua and Seriaa, 2015). board, managers, shareholders and other stakeholders - and lays down the rules and procedures for decision-making (stats.oecd.org, 2018)."

Berkenaaan dengan pentingnya konsep GCG dalam dunia perbankan, di Indonesia konsep GCG diperkenalkan pada tahun 1999 ketika pemerintah membentuk Komite Nasional untuk Tata Kelola Perusahaan (NCCG). Kode tata kelola perusahaan nasional diikuti pada tahun 2000 dan direvisi pada tahun 2006. Peraturan No. 8/4 / PBI / 2006 dikeluarkan secara khusus untuk menangani penerapan GCG di bank komersial dan direvisi oleh Peraturan Bank Indonesia No. 8/14 / PBI / 2006. Dalam rangka meningkatkan kepercayaan lokal maupun internasional terhadap sektor perbankanberbagai langkah kongkrit secara berkesinambungan telah dilakukan, termasuk melalui pengaturan Lembaga independent yaitu Otoritas Jasa Keuangan (OJK).

OJK dalam rangka rekomendasi konsep Basel II menetapkan standar minimum perbankan yang dapat diterima untuk risiko tingkat modal, 
profitabilitas dan implementasi GCG. Sebagai lembaga pengawas perbankan, OJK telah memperketat bisnis perbankan dalam hal ini BPR dengan menerapkan GCG dan manajemen resiko demi menghasikan kinerja yang lebih baik sebagaimana diatur dalam Peraturan OJK (POJK) No. 4/2015 tentang Penerapan Tata Kelola yang Baik bagi BPR, POJK No 13 /2015 tentang Penerapan Manajemen Risiko Bagi BPR dan SEOJK No. 7/SEOJK.03/2016 tentang Standar Pelaksanaan Fungsi Audit Intern BPR. Karena disadari bahwa dengan minimnya penerapan $G C G$ dan manajemen risiko membuat banyak BPR melakukan fraud (kecurangan) sehingga tidak sedikit BPR yang ditutup operasinya. Fraud yang terjadi lebih banyak akibat dari kurangnya pengendalian internal seperti kurangnya kompetensi Sumber Daya Manusia (SDM), kontrol yang tidak baik, check and balance, serta kurangnya action plan pengelola BPR. Penerapan GCG ini merupakan sebuah konsep yang menekankan pentingnya hak pemegang saham untuk memperoleh informasi dengan benar, akurat dan tepat waktu. Penerapan prinsip GCG sangat diperlukan agar perbankan dapat bertahan dan tangguh dalam menghadapi persaingan yang semakin ketat, serta dapat menerapkan etika bisnis, sehingga dapat mewujudkan iklim usaha yang sehat dan transparan. Tata kelola berbasis GCG sesungguhnya tidak hanya memperhatikan shareholder namun yang tidak kalah pentingnya adalah untuk kepentingan stakeholders dari sektor perbankan, yaitu yang mencakup: Transparency (Transparansi), Accountability (Akuntabilitas), Responsibility (Tanggung Jawab), Independency (Independensi), dan Fairness (Kewajaran dan Kesetaraan).

\section{b. Relevansi GCG dan Asas Itikad Baik dengan Kesehatan Bank}

Penilaian OJK terhadap GCG didasarkan pada tiga atribut, yaitu struktur tata kelola, proses tata kelola dan hasil tata kelola. Struktur tata kelola terdiri dari Komisaris, Direksi, dan Komite Penunjang. Implementasi GCG dalam konteks "struktur tata kelola" lebih diarahkan bahwa pelaksanaan GCG menghasilkan hasil yang sesuai dengan harapan para pemangku kepentingan bank.

GCG dalam perbankan tidak bisa dilepaskan dengan konsep "Governance Commitment." Komitmen ini dilakukan melalui Governance Structure sehingga pada akhirnya berpengaruh pada Governance Outcome. Melalui tahapan tersebut, kesehatan bank secara berkesinambungan diharapkan memenuhi kebutuhan stakeholders. Untuk menilai pencapaian bank, Governance outcome dipergunakan sebagai indikatornya (KNKG, 2012). Pencapaian tersebut diantaranya terjadi 
efiseinsi, taat terhadap ketentuan hukum, secara keseluruhan dominan dilandasi oleh melindungi konsumen, serta obyektif dalam hubungan hukum yang berbasis perjanjian, baik penilaian GCG dan self-assessment.

Dalam rangka mewujudkan Governance antara pemilik bank dengan karyawannya maupun antara pihak bank dengan nasabah, Outcome, prinsip dasar yang seyogyanya dalam konstruksi seperti itu keberadaan asas diterapkan meliputi: kesinambungan usaha, efisiensi, manfaat dan pelayanan, pentaatan terhadap peraturan dan ketentuan internal bank, berperan aktif dalam tanggung jawab social dan lingkungan, self-assessment yang obyektif, serta bank

memperoleh penilaian GCG yang baik dari otorita s pengatur dan pengawas bank dan penghargaan pelaksanaan GCG dari lembaga penilai GCG yan g memiliki reputasi yang baik.

Terkait dengan pelaksanaan GCG pada BPR, dalam rangka menuju capaian yang sesuai dengan prinsip dasar pencapaian Governance outcome, peran strategis Komisaris dalam perkembangannya sangat dibutuhkan. Penerapan itikad baik dari pengelolaan BPR dalam hal ini Komisaris sebagai wakil dari pemegang saham sangat penting, khususnya agar tidak adanya benturan kepentingan dalam pelaksanaan pengawasan BPR. Itikad baik adalah satu nilai yang menjadi tolok ukur dalam menentukan apakah suatu tindakan itu layak atau tidak untuk dilaksanakan. Itikad baik merupakan penyaring yang didasari oleh nilai moral dan kepatutan bagi itikad baik sangat diperlukan. Asas itikad baik pada dasarnya berasal dari sistem hukum kontrak civil law yang bersumber dari hukum Romawi, sementara itu sistem common law secara traadisional tidak mengenal asas itikad baik. Namun dalam perkembangannya Amerika Serikat sebagai salah satu negara yang menganut common law system mulai menerima asas itikad baik dalam sistem hukum kontraknya (Kolopaking, 2013). Sebagaimana dikemukakan sebelumnya, asas itikad baik berasal dari Romawi yaitu bona fides, mengandung arti berbuat dengan baik, jujur serta lurus (Hutabarat, 2008). Dalam hukum perjanjian di Indonesia, asas itikad baik tercantum dalam Pasal 1338 Ayat (3) Kitab Undang-Undang Hukum Perdata. Jika dicermati secara lebih mendalam sesungguhnya asas itikad baik juga mengejawantah dalam GCG yang juga relevan dikaitkan dengan prinsip NonDiscrimination System, dalam konteks ini transparansi sebagai salah satu perwujudannya (Dharmawan, 2015). Sehubungan dengan hal tersebut, menjadi sangat urgent semua komponen termasuk komisaris dalam pengelolaan bank operasional sebuah bank. Pengelolaan bank 
agar mengupayakan pelaksanaan prinsip GCG dalam rangka kesehatan bank.

Dalam realitanya tingkat kesehatan bank tidak dapat dilepaskan dari fungsi bank menghimpun dan menyalurkan kredit kepada masyarakat, termasuk penyaluran kredit pada BPR. Kredit perbankan diatur dalam Pasal 1 angka 11 Undang-Undang No. 10 Tahun 1998 Tentang Perbankan yang pada intinya menentukan dalam persetujuan pinjam meminjam tersebut antara bank dengan pihak lain yang dalam hal ini adalah nasabah bank, pihak peminjam wajib melunasi utangnya dalam jangka waktu yang disepakati beserta bunganya. Asas itikad baik dalam perjanjian kredit ini sangat diperlukan agar terwujud sistem perkreditan yang sehat. Asas itikad baik relevan dengan tata kelola yang baik, yaitu GCG.

Dengan adanya itikad baik dari Komisaris BPR dalam pengelolaan BPR, terutama demi tercapainya Governance Outcome yang ditetapkan merupakan suatu sikap menjaga nilainilai atau komponen GCG bisa diterapkan dengan baik pada BPR. Itikad baik sebagai suatu sikap atau nilai yang diimplementasikan oleh Komisaris dalam pengelolaan BPR merupakan nilai dasar dalam mendukung penerapan GCG dalam industri perbankan khususnya BPR. Semua itu bertujuan agar BPR dapat tetap bertahan dan tangguh dalam menghadapi persaingan yang semakin ketat, serta dapat menerapkan etika bisnis, sehingga dapat mewujudkan iklim usaha yang sehat dan transparan.

Komisaris menjaga keberlangsungan operasional BPR dalam hal ini pelaksanaan GCG dan manajemen risiko dengan baik, untuk menghindari adanya fraud (kecurangan). Komisaris memastikan pelaksanaan pengendalian internal terlaksana sesuai dengan baik, seperti terpenuhinya kompetensi Sumber Daya Manusia (SDM), check and balance, serta pelaksanaan action plan pengelola BPR. Melalui GCG, pihak pengelola dituntun untuk senantiasa secara transparan menginformasikan perkembangan BPR tidak hanya bagi kepentingan pemegang saham namun juga seluruh stakeholders terkait. Organ BPR seperti Komisaris atau Dewan Komisaris dalam konteks ini berperan mengawasi dan menginformasikan dengan benar, akurat dan tepat waktu perkembangan BPR. Regulasi yang berkaitan dengan GCG khususnya pada BPR secara berkesinambungan dilakukan penyempurnaan, seperti melalui mekanisme online OJK. Ketentuan yang berkaitan dengan transparansi pelaporan dan monitoring kepatuhan pelaporan secara online salah satunya dapat mengacu pada Pasal 23 POJK No. 37/POJK.03/2016 tentang Rencana Bisnis Bank Perkreditan Rakyat dan Bank Pembiayaan Rakyat Syariah. Transparansi pelaporan secara online 
sangat berkaitan erat dan membantu peran Komisaris dalam pengawasan pelaksanaan penentuan Rencana Bisnis BPR sampai dengan Realisasi Rencana Bisnisnya.

\section{Tanggungjawab Pengawasan Komisaris} dalam Rangka Kesehatan Bank dan Pengelolaan BPR

Komisaris sebagai wakil pemegang saham berperan penting dan memiliki tanggungjawab, khususnya berkaitan dengan pengelolaan BPR dalam rangka menumbuhkembangkan kesehatan BPR itu sendiri. Sebagai pengawas, Komisaris sedapat mungkin melakukan pemantauan dan pengawasan untuk menghindarkan terjadinya conflict of interest dalam rangka pengelolaan BPR yang mungkin terjadi antara Direktur dengan pemegang saham maupun pihak terafiliasi lainnya. Dengan demikian dapat dikemukakan bahwa terselenggaranya pelaksanaan GCG pada BPR tidak bisa dilepaskan dari tanggung jawab pengawasan yang dilakukan oleh Komisaris. Komisaris dalam fungsinya sebagai pengawas sedapat mungkin melakukan pemantauan dan melakukan mitigasi terhadap munculnya benturan kepentingan antara para pihak. Tanggung jawab pengawasan yang dilakukan oleh Komisaris juga berkaitan dengan memastikan bahwa keseluruhan aspek yang terkandung dalam GCG termasuk didalamnya pengawasan intern pada seluruh tingkatan dalam pengelolaan BPR terlaksana dan seluruh komponen melaksanakannya dengan itikad baik.

Jika dicermati secara lebih mendalam asas itikad baik tercermin melandasi tata kelola perbankan, termasuk pada BPR, khususnya tercermin melalui nilai-nilai etika pada perbankan pada umumnya maupun pada BPR pada khususnya. Berdasarkan Pasal 2 POJK No. 4/POJK.03/2015 Tentang Penerapan Tata Kelola Bagi Bank Perkreditan Rakyat diatur bahwa BPR wajib menerapkan Tata Kelola dalam setiap kegiatan usahanya pada seluruh tingkatan atau jenjang organisasi, yang juga mencakup pelaksanaan tugas dan tanggung jawab Dewan Komisaris. Lebih lanjut melalui Pasal 28 POJK ditegaskan tugas dan tanggung jawab Komisaris dilaksanakan secara independen. Artinya, tidak boleh ada benturan kepentingan yang muncul dalam pelaksanaan bisnis BPR. Tugas dan tanggung jawab pengawasan oleh Komisaris pada seluruh jenjang tata kelola juga ditegaskan kembali melalui Pasal 29 POJK. Dewan Komisaris wajib memastikan terselenggaranya penerapan Tata Kelola pada setiap kegiatan usaha BPR di seluruh tingkatan atau jenjang organisasi. Sehingga, Komisaris wajib mengarahkan, memantau, dan mengevaluasi penerapan GCG yang dilakukan oleh Dewan Direksi. Pengaturan terkait Dewan Komisaris dalam POJK ini tidak kurang dari 11 pasal. Hal ini 
didasari atas semakin meluasnya pelayanan disertai peningkatan volume usaha BPR, sehingga mengakibatkan semakin meningkat pula risiko BPR sehingga mendorong kebutuhan terhadap penerapan tata kelola oleh BPR yang baik dan lebih komprehensif. Termasuk pengaturan itu memperhatikan prinsip-prinsip dasar untuk menghindari adanya benturan kepentingan, misalnya: benturan kepentingan karena hubungan kekeluargaan, penyalahgunaan dalam penyususnan kebijakan atau keputusan strategis dan pemberian informasi yang menimbulkan inforasi yang asimetris, dan lainlain.

Pelaksanaan tugas dan tanggung jawab Komisaris BPR yang pada intinya mengawasi secara independen Dewan Direksi dalam pengeloaan operasional BPR. Secara obyektif Komisaris menjalankan tanggungjawabnya dalam rangka asas itikad baik dan GCG tercermin dari independensinya mengawasi dan bebas dari berbagai tekanan dan kepentingan. Komisaris melaksanakan tugas untuk kepentingan BPR secara menyeluruh dan sesuai dengan maksud dan tujuan BPR. Komisaris memiliki peran yang signifikan dalam pelaksanaan GCG pada BPR yang secara operasional dikelola Dewan Direksi untuk secara berkesinambungan mengusahakan tingkat kesehatan BPR yang terus meningkat dan berkelanjutan.

\section{C.SIMPULAN}

Komisaris sebagai wakil pemegang saham bertanggungjawab melaksanakan pengawasan secara independen dan fungsi kontrol dalam kaitannya dengan prinsip GCG dan asas itikad baik terhadap Dewan Komisaris dalam rangka tata pengelolan bank untuk meningkatkan kesehatan perbankan, termasuk BPR. Tugas dan tanggung jawab Komisaris BPR dalam mengawasi Dewan Direksi untuk mencapai tujuan utama BPR yaitu tercapainya kesehatan BPR. Komisaris dengan itikad baik bersikap obyektif dan bebas dari tekanan dan kepentingan pihak tertentu yang tidak sesuai dengan peraturan perundang-undangan, memastikan penerapan GCG dengan baik pada BPR, sehingga tercapainya Governance Outcome BPR. Komisaris memiliki peran yang signifikan dalam pelaksanaan GCG dan meminimalisasi terjadinya NPL pada BPR yang dikelola Dewan Direksi, sehingga memberikan nilai investasi yang memuaskan pemegang saham (shareholders).

\section{DAFTAR PUSTAKA}

\section{BUKU}

Kolopaking, Anita A. (2013). Asas Itikad Baik dalam Penyelesaian Sengketa Kontrak Melalui Arbitrase, Bandung : PT Alumni. 
Jurnal Law Reform

Volume 14, Nomor 2, Tahun 2018

Hutabarat, Samuel M.P. (2008). Penawaran dan

Penerimaan dalam Hukum Perjanjian. Jakarta: Grasindo.

Khairandy, Ridwan \& Malik, Camelia (2007). Good Corporate Governance:

Perkembangan Pemikiran Dan Implementasinya Di Indonesia Dalam Perspektif Hukum. Yogyakarat: Kreasi Total Media.

\section{JURNAL}

Cohn, A., Fehr, E. \& Maréchal, Michel André. (2014). Business Culture and Dishonesty In The Banking Industry, Nature, 516, p.19

Dharmawan, N. K. S., Landra, P. T. C. B., \& Samsithawrati, P. A. (2015). Penjabaran Standar Internasional TRIMs Dan OECD Dalam Ketentuan Hukum Penanaman Modal Indonesia. Jurnal Magister Hukum Udayana, Vol.4 (No. 3), pp. 550-564.

Emirzon, J. (2006). Regulatory Driven Dalam Implementasi Prinsip-Prinsip Good Corporate Governance Pada Perusahaan Di Indonesia. Jurnal Manajemen \& Bisnis Sriwijaya, vol.4 (No.8), pp. 93-114

Gumanti, M. (2017). Peran Otoritas Jasa Keuangan Terhadap Pengawasan Manajemen Operasional Perbankan Improper Behaviour (Bank Tidak Sehat). J urnal IImiah Ekonomi Manajemen"
Program Studi Magister Ilmu Hukum Fakultas Hukum Universitas Diponegoro

J urnal IImiah Multi Science", Vol.8 (No.2), p. 2

Putri, IGAMA., Ulupui, IGKA., Wirawati, NGP. (2017). Pengaruh Good Corporate Governance Dan Budaya Tri Hita Karana Pada Kinerja Bank Perkreditan Rakyat., J urnal IImiah Akuntansi Dan Bisnis, Vol. 12, (No. 1), pp.17-24.

Feldioreanua, IA., Seriaa, C. (2015). Corporate Governance Disclosure of Banks in Romania and Malaysia and the Quality of the Web Sites, Accounting and Management Information Systems, vol.14, (No.1), pp. 193-216

Komite Nasional Kebijakan Governance. (2012). Prinsip Dasar Pedoman Good Corporate Governance Perbanka n Indonesia, KNKG

Maturidi, Abu M. (2015). Analisa Pengaruh Kompetensi Dan Independensi Satuan Pengawas Internal Serta Penerapan Good Corporate Governance Terhadap Kinerja (Study Pada Bpr Di Pulau Lombok). Journal IImiah Rinjani_Universitas Gunung Rinjani Vol. 2, (No.2), pp.126-136.

Oroh, A. A. E., Kalangi, L., \& Wangkar, A. ( 2018). Analisis Peranan Internal Audit Dalam Mewujudkan Pelaksanaan Good Corporate Governance Pada PT. Bank Tabungan Negara, Tbk Manado. Jurnal Riset 
Akuntansi Going Concern, 13(03), pp. 1931

Mustofa, Ali. (2018). Pertumbuhan BPR

Melambat, Kredit Macet Naik Hingga 48

Persen, Kamis 24 Agustus 2018,

Https://Radarbali.Jawapos.Com/Read/2017 108/24/9378/Pertumbuhan-BPR-Melambat-

Kredit-Macet-Naik-Hingga-47-Persen.

Citta Maya (Bali Post), 2018, Karena Ini NPL BPR

Masih Tinggi, Rabu 23 Mei 2018,

Http://Www.Balipost.Com/News/2018/05/23

146194/Karena-Ini,Npl-BPR-Masih...Html

$<$ http:/Www.Tapestrynetworks.Com/Initiatives/Fin

ancial-Services/Bank-Governance-

Leadership-Network.Cfm>.

$<H t t p s: / / W w w . B i s . O r g / B c b s>$.

Walker, SD. (2014). Trust and Trustworthiness in

Banks and Bankers' (Speech Delivered at

The Federal Reserve Bank of New York

Workshop On Reforming Culture And

Behaviors in The Financial Services

Industry, 20 October $20 \quad 2014$

$<$ <ttps://Www.Newyorkfed.Org/Newsevents

/Events/Banking/2015/1105-2015.Html>.

Andrew Bailey, (Speech Delivered at The City

Banquet, London, 16 October 2014)

$<$ <ttp://Www.Bankofengland.Co.Uk/Publicat

ions/Documents/Speeches/2014/Speech76

3.Pdf>.

\section{PERATURAN PERUNDANG-UNDANGAN}

Kitab Undang-Undang Hukum Perdata Indonesia

Undang-Undang No. 10 Tahun 1998 tentang Perubahan Atas Undang-Undang No. 7 Tahun 1992 tentang Perbankan

POJK No. 4/POJK.03/2015 Tentang Penerapan Tata Kelola Bagi Bank Perkreditan Rakyat POJK No 13 /2015 tentang Penerapan Manajemen Risiko Bagi BPR

POJK No. 37/POJK.03/2016 tentang Rencana Bisnis Bank Perkreditan Rakyat dan Bank Pembiayaan Rakyat Syariah

SEOJK No. 7/SEOJK.03/2016 tentang Standar Pelaksanaan Fungsi Audit Intern BPR 